\title{
Eskişehir Ekolojik Koşullarında Rezene (Foeniculum vulgare Mill.) Uçucu Yağının Morfogenetik Varyabilitesinin Belirlenmesi
}

\author{
Nimet $\operatorname{KATAR}^{1}$, Duran $\operatorname{KATAR}^{2}$, Mustafa $\mathrm{CAN}^{3}$ \\ ${ }^{1}$ İl Tarım ve Orman Müdürlüğü-Eskişehir, ${ }^{2}$ Eskişehir Osmangazi Üniversitesi, Ziraat Fakültesi, Tarla Bitkileri Bölümü- Eskişehir, ${ }^{3}$ Eskişehir \\ Osmangazi Üniversitesi, Fen Bilimleri Enstitüsü- Eskişehir \\ ${ }^{1}$ https://orcid.org/0000-0003-0699-167X, ${ }^{2}$ https://orcid.org/0000-0003-1340-8040, ${ }^{3 h t t p s: / / o r c i d . o r g / 0000-0003-1533-7039 ~}$ \\ $\bowtie$ : nimetkatar@gmail.com
}

\section{ÖZET}

Eskişehir ekolojik koşullarında 2018 ve 2019 yıllarında yürütülen bu çalışmanın amacı, rezene (Foeniculum vulgare Mill) bitkisinin dört farklı organından (sap, yaprak, çiçek ve yeşil meyveler) elde edilen uçucu yağların oranlarını ve bileşenlerini belirlemektir. Tarla denemeleri tesadüf blokları deneme deseninde dört tekerrürlü olarak yürütülmüştür. İki yılın ortalamasına göre saplardaki, yapraklardaki, çiçeklerdeki ve kurutulmuş yeşil meyvelerdeki uçucu yağ oranlarının sırasıyla \% 1.10, \% 2.49, \% 5.51 ve \% 5.75 olduğunu göstermiştir. Sap, çiçek ve meyvelerden elde edilen uçucu yağlarda metilkavikol (sırasıyla \% 40.06, \% 71.06 ve \% 71.67) ana bileşen olarak belirlenirken, yapraklardan elde edilen uçucu yağda ise ana bileşen limonen (\% 41.34)'dir. Çalışmadan elde edilen veriler bitkinin değişik organlarına bağlı olarak uçucu yağ oranlarının ve uçucu yağların kimyasal kompozisyonunun farklılık gösterdiğini ortaya koymuştur.

\section{Araştırma Makalesi}

Makale Tarihçesi

Geliş Tarihi : 24.07 .2020

Kabul Tarihi : 02.02 .2021

\section{Anahtar Kelimeler}

Farklı bitki organları

Uçucu yağ oranı

Uçucu yağ kompozisyonu

Metilkavikol

Limonen

\section{Determination of Morphogenetic Variability of Fennel (Foeniculum vulgare Mill.) Essential Oil in Eskişehir Ecological Conditions}

\section{ABSTRACT}

The aim of this study, conducted in 2018 and 2019 years under the ecological conditions of Eskişehir, was to determine the content and components of essential oils obtained from four different organs (stems, leaves, flowers and green fruits) of fennel (Foeniculum vulgare Mill.). The field experiments were designed as randomized complete block design with four replications. The results showed that, as an average of two years, the essential oil content in stems, leaves, flowers and dried green fruits were $1.10 \%, 2.49 \%, 5.51 \%$ and $5.75 \%$, respectively. In essential oils obtained from stems, flowers and fruits, methylchavicol $(40.06 \%, 71.06 \%$ and $71.67 \%)$, respectively was determined as the main component, while in essential oil obtained from leaves, limonene (41.34\%) was the main compound. The data obtained from the study showed that essential oil contents and the chemical composition of essential oils differ depending on the plant's different organs.

\section{Research Article}

$\begin{array}{ll}\text { Article History } \\ \text { Received } & : 24.07 .2020 \\ \text { Accepted } & : 02.02 .2021\end{array}$

\author{
Keywords \\ Different plant organs \\ Essential oil content \\ Essential oil composition \\ Methylchavicol \\ Limonene
}

\footnotetext{
Atıf için: $\quad$ Katar N, Katar D, Can M 2021. Eskişehir Ekolojik Koşullarında Rezene (Foeniculum vulgare Mill.) Bitkisinin Morfogenetik Varyabilitesinin Belirlenmesi. KSÜ Tarım ve Doğa Derg 24 (5): 1021-1028. DOI: 10.18016/ ksutarimdoga.vi.773567.

To Cite: $\quad$ Katar N, Katar D, Can M 2021. Determination of Morphogenetic Variability of Fennel (Foeniculum vulgare Mill.) Essential Oil in Eskişehir Ecological Conditions. KSU J. Agric Nat 24 (5): 1021-1028. DOI: 10.18016/ksutarimdoga.vi.773567.
}

\section{GİRIŞ}

Apiaceae (Umbelliferae) familyasina ait olan rezene (Foeniculum vulgare Mill.) çok eskiden beri bilinen önemli bir tıbbi ve aromatik bitkidir (Khorshidi ve ark., 2009; He ve Huang, 2011; Shubham, 2019; Açıkgöz ve Kara, 2020). Apiaceae familyası dünyada yayılış gösteren 300 cins ve bu cinslere bağlı yaklaşık 3000 türe sahiptir (Çalışkan ve ark., 2010). Geçmişten beri insanlar tarafindan bilinen ve kendisinden yararlanılan rezene Akdeniz havzasının yerel bitkisi olup, tarımı dünyanın ılıman ve tropikal bölgelerinde (Almanya, İspanya, İtalya, Hollanda, Fransa, 
Hindistan, Çin, Fas, Bulgaristan, Yunanistan, Romanya, İsviçre ve Arjantin, İngiltere, İran, Vietnam ve Güney Amerika'da) yaygın bir şekilde yapılmaktadır (Khorshidi ve ark., 2009; Rather ve ark., 2016; Badgujar ve ark., 2014; Al-Snafi, 2018).Türkiye'de ise rezene, başta Güney ve Batı Anadolu olmak üzere, Kuzey Anadolu'nun doğal florasında yer almakta olup, aynı zamanda ülkemizin batı ve güney bölgelerinde kültürü de yapılmaktadır (Çalışkan ve ark., 2010).

Halk hekimliğinde bitkinin kök, gövde kabukları, yaprak, çiçek ve tohum gibi değişik organları farklı rahatsızlıkların tedavisinde kullanılmaktadır (Shubham, 2019). Rezene bitkisinin meyveleri mutfaklarda çorbalara, soslara, turşulara, ekmek ve kek gibi hamur işlerine lezzet kazandırmak için kullanıldığı gibi hazır gıda endüstrisinde de gıdalara lezzet kazandırmak veya da gıdaların raf ömrünü uzatmak amaciyla baharat olarak kullanılmaktadır. Aynı zamanda bitkinin toprak üstü aksamından da sebze olarak değişik şekillerde yararlanılmaktadır (Khorshidi ve ark., 2009; Coban ve ark., 2018; Giachino ve Avc1, 2020). Halk hekimliğinde bitkinin kökleri idrar söktürücü ve yaprakları yara iyilestirici olarak kullanılmaktadır (Çalışkan ve ark., 2010). Bitkinin meyveleri üzerinde yürütülen çalışmalar idrar söktürücü, ağrı kesici, antioksidan, karaciğer koruyucu, spazm çözücü, iltihap kurutucu, kabızlık giderici, balgam söktürücü, akarisit, anthirsutizm/kıl dökücü, antiplatelet, antikoagülan, antitromboz, hipotansif, östrojenik, repellent, diyabet ve tümör önleyici, kolesterol düşürücü, sindirim sistemini düzenleyici, nörolojik hastalıkları tedavi edici ve süt arttırıcı etkilere sahip olduğunu göstermiştir (Moura ve ark., 2005; Khorshidi ve ark., 2009; Shubham, 2019; Çalışkan ve ark., 2010). Ayrıca bitkinin yapraklarından, çiçeklerinden ve meyvelerinden son yıllarda herbal çay üretiminde yararlanılmaktadır. Herbal çay ve baharat olarak kullanımda ürünün en önemli kalite kriteri materyalin içermiş olduğu uçucu yağ oranıdır. Bitkinin iki alt türü (Foeniculum vulgare Miller subsp. vulgare ve $F$. vulgare Miller subsp. piperitum (Ucria) Coutinho) bulunmaktadir. Bunlardan Foeniculum vulgare Miller subsp. vulgare alt türü ise dört farklı varyete içermektedir $\mathrm{Bu}$ varyetelerden ikisi ( $F$. vulgare var. vulgare (acı rezene) ve $F$. vulgare var. dulce (Miller) Thellung (tatlı rezene), farmasötik açıdan önemli olup, farmakope ve monograflarda kayıtlıdır. Diğer iki varyete ise sebze olarak kullanılmaktadır (Çalışkan ve ark., 2010). Yapılan çalışmalarda kullanılan materyalin acı rezene (F. vulgare Miller subsp. vulgare var. vulgare) veya tatll rezene ( $F$. vulgare Miller subsp. vulgare var. dulce) olmasına bağlı olarak uçucu yağ oranları farklılık göstermektedir. Uçucu yağ oranı acı rezene de \% 3-6 arasında değişirken, tatlı rezenede ise \% 2-4 arasında değişim göstermiştir (Giachino ve Avcı,
2020). Avrupa farmakopesinde rezene meyvesinin uçucu yağ alt sınır değerleri acı rezenede \% 4, tatlı rezenede ise \% 2 olarak bildirilmiştir (Çalışkan ve ark., 2010).

Meyvelerinden elde edilen uçucu yağı ise kozmetik, parfümeri ve ilaç endüstrisinin önemli bir hammaddesini oluşturmaktadır (Rather ve ark., 2016; Punetha ve ark., 2019). Diğer tıbbi ve aromatik bitkilerde olduğu gibi rezene bitkisinin tıbbi, aromatik ve farmakolojik özellikleri büyük oranda içerdiği uçucu yağın kimyasal kompozisyonunda yer alan bileşenlerin çeşitliliği ve bu bileşenlerin uçucu yağ içerisindeki miktarları tarafından belirlenmektedir (Khan ve Musharaf, 2014; Bhardwaj ve ark., 2019). Rezene uçucu yağının biyoaktivitesi üzerinde yürütülen çalışmalar, uçucu yağın antioksidan (Kara ve Açıkgöz, 2018; Açıkgöz ve Kara, 2020), antienflamatuar (Choi ve Hwang, 2004; Al-Snafi, 2018), antibakteriyel (Çalışkan ve ark., 2010; Açıkgöz ve ark., 2017) ve antifungal (Çalışkan ve ark., 2010) özelliklere sahip olduğunu ortaya koymuştur. Rezene meyvelerinden elde edilen uçucu yağının ana bileşenlerinin trans-anethole (anothole-E), estragole (methyl chavicol), a-phellandrene, fenchone, a-pinene ve limonen olduğu belirlenmiştir (Rather ve ark., 2016; Açıkgöz ve Kara, 2020). Türkiye'de Orta Karadeniz Bölgesinden toplanan yabani rezene popülasyonlarının uçucu yağlarında ana bileşenlerinin estragole ve fenchone olduğu bildirilmiştir (Telci ve ark., 2019). Diğer taraftan rezenin Foeniculum vulgare subsp. piperitum alttürü kullanılarak yapılan bir çalışmada yıllara bağlı olarak (2001 ve 2002) ana bileşenlerinin ve oranlarının methyl chavicol (\% 40.29 ve 21.69$)$, limonene (\% 17.66 ve 22.24$)$, fenchone (\% 16.90 ve 12.98$)$, $\alpha$-pinene (\% 1.86 ve 34 ) and $\alpha^{-}$ phellandrene (\% 2.30 ve 2.74 ) olduğu tespit edilmiştir (Özcan ve Chalchat, 2006). Rezene üzerinde yürütülen bir diğer çalışmada uçucu yağın ana bileşenlerinin anethol ve fenchon olduğu ve uçucu yağın kimyasal kompozisyonun hem bitkinin kullanılan kısmina ve hem de hasat mevsimine (dönemine) bağll olarak değişiklik gösterdiği belirtilmiştir (Moura ve ark., 2005). Avrupa Farmakopesinde ise uygun acı rezene yağının en az \% 60 anetol, en az \% 15 fenkon ve tatlı rezenenin en az \% 80 anetol içermesi gerektiği ifade edilmiştir (Çalışkan ve ark., 2010).

Aromatik bitkilerde uçucu yağ oranı ve uçucu yağın kimyasal kompozisyonu üzerinde etkili olan faktörler, iç ve dış faktörler olmak üzere iki grupta incelenmektedir (Katar ve ark., 2019). İç faktörleri, üretim materyali olarak kullanılan bitkilerin sahip olduğu genetik yapı temsil etmektedir (Reily, 2013; Açıkgöz ve Kara, 2020). Dı̧̧ faktörler ise kendi içerisinde iki gruba ayrılmakta olup, bunlar üretimin yapıldığı bölgenin iklim ve toprak koşullarını temsil eden ekolojik faktörler ve yetiştiricilik esnasında uygulanan agronomik işlemlerdir (Al-Snafi, 2018; 
Punetha ve ark., 2019). Ayrica aromatik bitkilerin farklı organları farklı düzeylerde ve farklı bileşenlere sahip uçucu yağlar içermektedir (Wahba ve ark., 2018; Açıkgöz ve Kara, 2020).

Rezene, farklı organları (kök, sap, yaprak, çiçek tomurcuğu, çiçek ve farkl gelişim aşamalarındaki meyveler) ticarete konu olan önemli bir tıbbi aromatik bitkidir (Stefanini ve ark., 2006). Bu nedenle bitkinin farklı organlarının içermiş olduğu sekonder metabolitlerin oran ve bileşenlerinin bilinmesi bu organların ticari değeri açısından büyük öneme sahiptir (Khan ve Musharaf, 2014, Açıkgöz ve Kara, 2020). Çünkü ister bitkinin farklı organları drog olarak kullanılsın, isterse bu organlardan elde edilen uçucu yağlar kullanılacak olsun ürünün kullanım alanını ve dolayısıyla da fiyatını belirleyen en önemli faktör ürünün içerdiği etkili madde oranı ve etkili maddenin kompozisyonudur (Açıkgöz ve Kara, 2020). $\mathrm{Bu}$ nedenle bitkinin farklı organlarından elde edilen ürünlerin uçucu yağ oranının ve bu taze organlardan elde edilecek kuru herba miktarının belirlenmesi büyük öneme sahiptir.

Eskişehir kuru tarım koşullarında rezene bitkisi ile ilgili çalışmaların kısıtlı olması sebebiyle; 2018 ve 2019 yıllarında yürütülen mevcut çalışmada, rezenenin (Foeniculum vulgare Mill) farklı bitki aksamındaki (sap, yaprak, çiçek ve yeşil meyveler) uçucu yağ oranlarını ve uçucu yağların kimyasal kompozisyonunu belirlemek amaçlanmıştır.

\section{MATERYAL ve METOD}

Kütahya Hekim Sinan Tıbbi ve Aromatik Bitkiler Bahçesinden temin edilen acı rezene (Foeniculum vulgare Miller var. vulgare) bitkisinin tohumları denemede bitkisel materyal olarak kullanılmıştır. Bu çalışmanın tarla denemesi Eskişehir Orman Bölge Müdürlügü’ne ait fidanlık arazisinde 2018 ve 2019 yıllarında yürütülmüştür. Tarla denemesinin yürütüldüğü parselden alınan toprak örneklerinin analizleri yapılmış ve toprağın bazı özellikleri Çizelge 1'de verilmiştir. Deneme alanı toprağının tekstürü tınlı bir yapıya sahip olup, hafif alkalin, orta kireçli ve organik madde içeriği düşük bir durumdadır.

Bölgenin 2018, 2019 ve uzun yıllara ait aylık yağış ve sıcaklık değerleri Çizelge 2'de verilmiştir. 2018 ve 2019 yıllarına ait toplam yağış miktarları sırasıyla 411.8 ve $426.8 \mathrm{~mm}$ olup, her iki yılda da alınan yağış miktarı uzun yılların yağış miktarına $(338.8 \mathrm{~mm})$ kıyasla yüksektir. Çalışma yıllarının ortalama sıcaklıkları ise $12.5{ }^{\circ} \mathrm{C}$ ve $12.8{ }^{\circ} \mathrm{C}$ olup, uzun yillarin ortalama sıcaklığına $\quad\left(10.7 \quad{ }^{\circ} \mathrm{C}\right) \quad$ nisbetle daha yüksek gerçekleşmiştir.

Çizelge 1. Deneme alanı toprağının bazı özellikleri

Table 1. Some properties of experiment area soil

\begin{tabular}{|c|c|c|c|c|c|c|}
\hline $\begin{array}{l}\text { Tekstür } \\
\text { (Texture) }\end{array}$ & $\begin{array}{l}\text { Kireç(\%) } \\
\text { Lime } \\
(\%)\end{array}$ & $\begin{array}{l}\text { Tuz }(\%) \\
\text { Salt } \\
(\%)\end{array}$ & $\begin{array}{c}\text { Yarayısll fosfor }\left(\mathrm{P}_{2} \mathrm{O}_{5}\right) \text { (ppm) } \\
\text { Available phosphorus } \\
\left(\mathrm{P}_{2} \mathrm{O}_{5}\right) \text { (ppm) }\end{array}$ & $\begin{array}{l}\text { Toplam azot (\%) } \\
\text { Total nitrogen } \\
\text { (\%) }\end{array}$ & $\begin{array}{l}\mathrm{pH} \\
(p H)\end{array}$ & $\begin{array}{l}\text { Organik madde }(\%) \\
\text { Organic matter }(\%)\end{array}$ \\
\hline $\begin{array}{l}\text { Tinlı (2018) } \\
\text { Loam (2018) }\end{array}$ & 8.46 & 0.22 & 36.00 & 0.13 & 7.6 & 1.73 \\
\hline $\begin{array}{l}\text { Tinlı (2019) } \\
\text { Loam (2019) }\end{array}$ & 7.87 & 0.20 & 33.00 & 0.17 & 7.4 & 1.54 \\
\hline
\end{tabular}

Toprak analizi Geçit Kuşağı Tarımsal Araştırma Enstitüsü Toprak-Bitki-Su analizi ve Fizyoloji laboratuvarında yapılmıştır.

Çizelge 2. Deneme alanının 2018-2019 ve uzun yıllar aylık sıcaklık ve yağış değerleri

Table 2. Monthly temperature and precipitation values of the experiment area for 2018-2019 and long years

\begin{tabular}{|c|c|c|c|c|c|c|}
\hline \multirow{2}{*}{$\begin{array}{l}\text { Aylar } \\
\text { (Months) }\end{array}$} & \multicolumn{3}{|c|}{ Toplam yağ ${ }_{1 s ̧}(\mathrm{~mm})$ (Total precipitation) } & \multicolumn{3}{|c|}{ Ortalama sicaklık $\left({ }^{\circ} \mathrm{C}\right)$ (Mean temperature) } \\
\hline & $\begin{array}{l}\text { Uzun yillar* } \\
\text { (Long years) }\end{array}$ & 2018 & 2019 & $\begin{array}{l}\text { Uzun yillar* } \\
\text { (Long years) }\end{array}$ & 2018 & 2019 \\
\hline Ocak (January) & 30.6 & 30.0 & 40.3 & -0.2 & 1.4 & 1.7 \\
\hline Şubat (February) & 26.1 & 28.8 & 51.5 & 0.9 & 5.6 & 4.1 \\
\hline Mart (March) & 27.6 & 49.8 & 13.3 & 4.9 & 8.9 & 7.3 \\
\hline Nisan (April) & 43.1 & 16.8 & 38.6 & 9.6 & 13.6 & 10.2 \\
\hline Mayıs (May) & 40.0 & 72.0 & 30.3 & 14.9 & 16.4 & 17.4 \\
\hline Haziran (June) & 23.7 & 60.6 & 57.5 & 19.1 & 19.3 & 21.1 \\
\hline Temmuz (July) & 13.1 & 42.0 & 17.4 & 22.1 & 21.9 & 21.8 \\
\hline Ağustos (August) & 9.2 & 19.3 & 2.9 & 21.8 & 22.7 & 22.7 \\
\hline Eylül (September) & 18.1 & 3.8 & 6.6 & 16.7 & 18.3 & 18.8 \\
\hline Ekim (October) & 32.8 & 30.1 & 69.9 & 11.7 & 13.0 & 15.2 \\
\hline Kasım (November) & 34.0 & 18.6 & 22.4 & 5.6 & 7.4 & 9.9 \\
\hline Aralık (December) & 40.5 & 40.0 & 76.1 & 1.7 & 1.7 & 3.3 \\
\hline Toplam (Total) & 338.8 & 411.8 & 426.8 & - & & \\
\hline Ortalama (Mean) & - & - & - & 10.7 & 12.5 & 12.8 \\
\hline
\end{tabular}

Kaynak: Eskişehir Meteoroloji Bölge Müdürlüğü *1970-2011 yılları arası 
Tarla, 2016 yılının sonbahar mevsiminde pullukla 30 $\mathrm{cm}$ derinden sürülerek kışa terk edilmiş ve 2017 yılı ilkbaharında uygun bir tohum yatağı temin etmek için diskaro ve merdane çekilerek hazırlanmıştır. Hazırlanmış olan deneme parseline tohumlar 20.03.2017 tarihinde sira arası $50 \mathrm{~cm}$ olacak sekilde ve dekara $1 \mathrm{~kg}$ tohumluk hesabıyla 2-3 $\mathrm{cm}$ derinliğinde açılan sıralara elle ekilmiştir. Çıkış sonrası bitkiler 45 yapraklı olduğunda sira üzeri mesafe $30 \mathrm{~cm}$ olacak şekilde seyreltilmiştir. Deneme tesadüf blokları deneme desenine göre 4 tekerrürlü olarak kurulmuştur. Her blok 4 parsel (sap hasadı, yaprak hasadı, çiçek hasadı ve yeşil meyve hasadı) içermektedir. Bloklarda bulunan parsellerin uzunluğu $5 \mathrm{~m}$ olup, her parselde 4 sıra bitki yer almıştır. Bitkilerin su ihtiyacı dikkate alınarak damla sulama yöntemiyle sulama yapılmıştır. Yabancı ot mücadelesi de yine yabancı otların gelişim durumu dikkate alınarak el çapasıyla yapılmıştır. 2017 yılında, $3 \mathrm{~kg} / \mathrm{da}$ saf $\mathrm{N}$ ve $6 \mathrm{~kg} / \mathrm{da}$ saf $\mathrm{P}_{2} \mathrm{O}_{5}$ gübre ekimden önce toprağa uygulanarak karıştırılmıştır. 2018 ve 2019 yıllarında ise $5 \mathrm{~kg} / \mathrm{da}$ saf $\mathrm{N}$ hesabiyla ilkbaharda bitkiler uyanırken azotlu gübre uygulaması yapılmıştır (Khorshidi et al., 2009). Bitkilerin sap, yaprak ve çiçek hasatları bitkilerin tam çiçek açtığı 01.09.2018 ve 03.09.2019 tarihlerinde yapılırken, yeşil meyvelerin hasadı ise 20.10.2018 ve 24.10.2019 tarihlerinde yapılmıştır. Hasat edilen taze materyallerden ayrılan 1 kg'llk örnekler $38-40{ }^{\circ} C^{\prime}$ lik etüvde 48 saat süreyle kurutulmuş ve daha sonra kuru ağırlıkları tartılmıştır. Buradan da \% olarak taze materyallerden elde edilen kuru materyal oranı hesaplanmıştır. Kurutulmuş materyallerden alınan örneklerin uçucu yağ oranları su distilasyonu yöntemi ile Clevenger aparatı kullanılarak belirlenmiştir. Uçucu yağların distilasyonu için ayıklanmış ve kurutulmuş $100 \mathrm{~g}$ örnekler 2000 ml'lik balonlara yerleştirildikten sonra $1000 \mathrm{ml}$ saf su eklenerek 3 saat boyunca distilasyon işlemi gerçekleştirilmiştir. Distilasyon işlemi tamamlandıktan sonra clevenger aparatının dereceli kısmından yağ miktarı okunmuş ve yüzde (\%) olarak belirlenmiştir. Clevenger cihazından alınan uçucu yağlar bileşenlere bakılacağı zamana kadar $3-4^{\circ} \mathrm{C}$ sıcaklıktaki buzdolabında saklanmıştır.

Uçucu yağların bileşenleri çalışma koşulları aşağıda verilen GC/MS cihazıyla Batı Akdeniz Tarımsal Araştırma Enstitüsü Müdürlüğü/Tıbbi Araştırmalar Merkezi Laboratuvar'inda belirlenmiştir. Örnekler analiz edilmek üzere 1:100 oranında hekzan ile seyreltilmiştir. Örneklerin uçucu yağ bileşen analizi GC/GC-MS (Gaz kromatografisi (Agilent 7890A)-kütle detektör (Agilent 5975C)) cihazı ile kapiler kolon (HP InnowaxCapillary; $60.0 \mathrm{~m} \times 0.25 \mathrm{~mm} \times 0.25 \mu \mathrm{m}$ ) kullanılarak gerçekleştirilmiştir. Analizde taşıyıcı gaz olarak $0,8 \mathrm{ml} / \mathrm{dk}$ akış hızında helyum kullanılmış, örnekler cihaza 1 pl olarak 40:1 split oranı ile enjekte edilmiştir. Enjektör sıcaklığ $250^{\circ} \mathrm{C}$ 'de tutulmuş, kolon sicaklık programı $60^{\circ} \mathrm{C}$ (10 dakika), $60^{\circ} \mathrm{C}$ 'den $250^{\circ} \mathrm{C}$ 'ye $20^{\circ} \mathrm{C} /$ dakika ve $250^{\circ} \mathrm{C}$ (10,5 dakika) olacak şekilde ayarlanmıştır. $\mathrm{Bu}$ sıcaklık programı doğrultusunda toplam analiz süresi 30 dakika olmuştur. Kütle detektörü için tarama aralığ $\breve{1}_{1}(\mathrm{~m} / \mathrm{z}) \quad 35-450$ atomik kütle ünitesi ve elektron bombardımanı iyonizasyonu $70 \mathrm{eV}$ kullanılmıştır. Uçucu yağın bileşenlerinin teşhisinde ise WILEY ve OIL ADAMS kütüphanelerinin verileri esas alınmıştır. Sonuçların bileşen yüzdeleri FID dedektör kullanılarak, bileşenlerin teşhisi ise MS dedektör kullanılarak yapılmıştır.

Uçucu yağ ve taze materyalde kuru herba oranlarına ait veriler SPSS paket programında tesadüf blokları deneme desenine göre varyans analizine tabi tutularak incelenen özelliklerin önemlilik düzeyleri belirlenmiştir. Önemli çıkan uygulamalar arasındaki farklılıklar TUKEY testine göre gruplandırılmıştır (Açılkgöz ve ark., 1993).

\section{BULGULAR ve TARTIŞMA}

Rezene bitkisinin farklı organlarının, yılların ve yıl x farklı organ interaksiyonunun (kuru herba/taze herbada) x 100 (\%) oranı üzerinde $\mathrm{p} \leq 0.01$ düzeyinde önemli etkiye sahip olduğu tespit edilmiştir (Çizelge 3). Her iki yılda da en yüksek kuru herba oranı sirasıyla \% 44.83 ve \% 39.38 ile yeşil meyvelerde elde edilmiştir. En düşük oran ise sirasıyla \% 12.00 ve \% 11.05 ile yapraklarda belirlenmiştir. Yılların ortalaması olarak ise bu değerler yine aynı organlarda en yüksek \% 42.10 ve en düşük \% 11.53 olarak belirlenmiştir. Sap ve çiçek için ise iki yılın ortalaması olarak kuru herba oranları sırasiyla \% 38.98 ve \% 28.34 olarak kayıt edilmiştir. Bitki organlarına bağlı olarak kuru herba oranlarında ortaya çıkan farklılıklar bitkinin farklı organlarının hasat edildiği anda içermiş olduğu su miktarlarının farklılığıyla açıklanabilir. En yüksek kuru drog oranının elde edildiği yeşil meyvelerin ve yeşil yaprakların hasat anında içerdikleri su oranları dikkate alındığında bu durum daha iyi anlaşılmaktadır. Bu değerler bize yapraktan sonra en fazla su oranına çiçeklerin sahip olduğunu göstermektedir. Kuru herba oranında yıllar arasında görülen fark ise yıllara bağlı olarak değişen iklim koşullarıyla (özellikle ilkbaharda bitkilerin ilk gelişmeye başladığı nisan ayında ortalama sıcaklığın 2018 yılında 2019 yılına göre daha yüksek gerçekleşmesi) açıklanabilir.

Yapılan istatistik analizde yılların uçucu yağ oranı üzerinde $p \leq 0.05$ düzeyinde önemli etkiye sahip olduğu belirlenmiştir. 2018 yılında uçucu yağ oranı \% 3.84 olarak belirlenirken, 2019 yllında ise \% 3.58 olarak tespit edilmiştir. Yıllara bağlı olarak uçucu yağ oranında meydana gelen değişim, iklim koşullarının özellikle bitkinin hasat edildiği dönemde meydana gelen aylık yağış miktarlarının ve ortalama 
sıcaklıkların farklılaşmasıyla açıklanabilir. Yıl x farklı bitki organları interaksiyonun uçucu yağ oranı üzerindeki etkisi istatistiki olarak önemsiz bulunmuştur. Her iki yetiştirme yılında en yüksek ve en düşük uçucu yağ oranının aynı bitki organlarından elde edilmesi yıl $\mathrm{x}$ farklı bitki organları interaksiyonunun istatistiksel olarak önemsiz olduğunu göstermektedir (Çizelge 3). Uçucu yağ oranları değişen bitki organlarına bağlı olarak $\mathrm{p} \leq 0.01$ düzeyinde önemli farklılık göstermiştir. İki yılın ortalaması olarak uçucu yağ oranına ait değerlerin bitki organlarına bağlı olarak değişimi incelendiğinde en yüksek uçucu yağ oranı meyvede (\% 5.75) ve çiçekte (\% 5.51) tespit edilirken en düşük oran ise \% 1.10 ile bitkinin saplarında tespit edilmiştir. Bitkinin organlarında uçucu yağ oranının sap<yaprak<çiçek<meyve sıralamasıyla artış gösterdiği belirlenmiştir. Bitkinin yapraklarında ise \% 2.49 oranında uçucu yağ oranı bulunmuş̧tur. Yılların ve farklı bitki organlarının ortalaması olarak ise \% 3.71 uçucu yağ oranı kaydedilmiştir (Çizelge 3). Uçucu yağ oranlarının bitki organlarına bağlı olarak değişim gösterdiği daha önce yürütülen çalışmalarda da belirtilmiştir (Bernath ve ark., 1999; Chung ve ark.,
1999). Bitki organlarına bağlı olarak uçucu yağ oranlarının değişimi, organların yapısal ve fizyolojik farklılıklarla açıklanabilir. Nitekim meyvenin oluşumu sırasında ve yağ kanallarının nispi oranının yüksek olduğu ve asimilatların birikiminin henüz başlamadığı meyvenin erken gelişme aşamalarında yağ oranınının yüksek olduğu rapor edilmiştir (Bernath ve ark., 1999). Bitki organlarına bağlı olarak meydana gelen yapısal farklılıklar nedeniyle her organda uçucu yağ sentezlenen ve depolanan yağ hücreleri veya kanallarının yoğunluğu, iriliği ve şekil farklılıkları uçucu yağ oranı üzerinde etkili olmaktadır. Ayrıca sekonder metabolit sentezinin yoğunluğu da bitkinin organlarına bağlı olarak değişkenlik göstermektedir (Bernath ve ark., 1999; Chung ve ark., 1999; Stefanini ve ark., 2006; Mammadov, 2014).

Bu çalışmadan elde edilen bitki organlarındaki uçucu yağ oranı bakımından tespit edilen sap<yaprak<çiçek<meyve sıralaması Açıkgöz ve Kara (2020)'nın bildirmiş olduğu meyve > çiçek > kökyumru-sap > yaprak siralamasiyla benzerlik göstermiştir.

Çizelge 3. Rezene (Foeniculum vulgare Mill) 'de farklı bitki organlarında tespit edilen kuru herba ve uçucu yağ oranları (\%)

Table 3. Dry herb and essential oil contents (\%) determined in different plant organs in fennel (Foeniculum vulgare Mill)

\begin{tabular}{|c|c|c|c|c|c|c|}
\hline \multirow[t]{2}{*}{$\begin{array}{l}\text { Bitki organı } \\
\text { (Plant organ) }\end{array}$} & \multicolumn{3}{|c|}{$\begin{array}{l}\text { Kuru herba oranı (\%) } \\
\text { (Dry herb content) }\end{array}$} & \multicolumn{3}{|c|}{$\begin{array}{l}\text { Uçucu yağ oranı }(\%) \\
\text { (Essential oil content) }\end{array}$} \\
\hline & 2018 & 2019 & $\begin{array}{l}\text { Ortalama } \\
\text { (Mean) }\end{array}$ & 2018 & 2019 & $\begin{array}{l}\text { Ortalama } \\
\text { (Mean) }\end{array}$ \\
\hline Çiçek (Flower) & $29.05 \pm 0.62 \mathrm{c}$ & $27.63 \pm 0.67 \mathrm{~b}$ & $28.34 \pm 0.50 \mathrm{c}$ & $5.75 \pm 0.62$ & $5.28 \pm 0.19$ & $5.51 \pm 0.16 \mathrm{a}$ \\
\hline Yaprak (Leaf) & $12.00 \pm 0.74 \mathrm{~d}$ & $11.05 \pm 0.67 \mathrm{c}$ & $11.53 \pm 0.49 \mathrm{~d}$ & $2.50 \pm 0.15$ & $2.48 \pm 0.18$ & $2.49 \pm 0.11 \mathrm{~b}$ \\
\hline Sap (Stem) & $40.83 \pm 0.65 \mathrm{~b}$ & $37.13 \pm 0.61 \mathrm{a}$ & $38.98 \pm 0.81 \mathrm{~b}$ & $1.13 \pm 0.05$ & $1.08 \pm 0.03$ & $1.10 \pm 0.03 \mathrm{c}$ \\
\hline Yeşil meyve(Green fruit) & $44.83 \pm 0.65 \mathrm{a}$ & $39.38 \pm 0.40 \mathrm{a}$ & $42.10 \pm 1.09 \mathrm{a}$ & $6.00 \pm 0.09$ & $5.50 \pm 0.09$ & $5.75 \pm 0.11 \mathrm{a}$ \\
\hline Ortalama (Mean) & $31.68 \pm 3.31 \mathrm{~A}$ & $28.79 \pm 2.89 \mathrm{~B}$ & $30.23 \pm 2.17$ & $3.84 \pm 0.54 \mathrm{~A}$ & $3.58 \pm 0.49 \mathrm{~B}$ & $3.71 \pm 0.36$ \\
\hline F değeri (yıl) $F$ value (year) & $1258.000 * *$ & & & $30.767^{*}$ & & \\
\hline $\begin{array}{l}\text { F değeri ( } F \text { value) } \\
\text { (Morphogenetic variability) }\end{array}$ & $4304.000 * *$ & & & $477.107^{* *}$ & & \\
\hline $\begin{array}{l}\mathrm{F} \text { değeri (yıl } \mathrm{x} \text { m. varyabilite) } \\
F \text { value (year } x \text { m.variability) }\end{array}$ & $24.731^{* *}$ & & & 1.542öd & & \\
\hline
\end{tabular}

*: $\mathrm{p} \leq 0.05$ düzeyinde önemli, ${ }^{* *}: \mathrm{p} \leq 0.01$ düzeyinde önemli, öd : önemli değil

Rezene bitkisinde üretimde kullanılan bitkinin alt tür ve varyetesine bağlı olarak elde edilen uçucu yağın kimyasal kompozisyonu farklılık gösterdiği gibi uçucu yağın elde edildiği organların farklı oluşuna bağlı olarak ta değişiklik arz etmektedir (Bernath ve ark., 1999; Chung ve ark., 1999; Stefanini ve ark., 2006; Mammadov, 2014; Açıkgöz ve Kara, 2020). Eskişehir koşullarında yürütülen çalışmadan elde edilen uçucu yağların kimyasal kompozisyonları Çizelge 4'te sunulmuştur. Bitkinin çiçeklerinden elde edilen uçucu yağda metilkavikol (\% 71.06), fenkon (\% 15.81) ve limonen (\% 6.95) ana bileşenler olarak tespit edilmiştir. Yapraklarında ise limonen (\% 41.34), metilkavikol (\% 23.00), $\alpha$-phellandren $(\%$ 17.43) ve fenchyl asetat (\% 6.61) ana bileşenler olarak dikkat çekmiştir. Bitkinin saplarında ise metilkavikol (\% 40.06), a phellandren (\% 13.87), limonen (\% 13.21), karvakrol (\% 11.60), fenchyl asetat (\% 8.05) ve fenkon (\% 6.49) ana bileşen olarak ön plana çıkmıştır. Kurutulmuş yeşil meyvelerinde ise metilkavikol (\% 71.67), fenkon (\% 17.85) ve limonen (\% 4.03) ana bileşen olarak belirlenmiştir. $\mathrm{Bu}$ değerlerden görüldüğü gibi bitkinin farlı organlarından elde edilen uçucu yağların kompozisyonunda varyasyon oldukça yüksektir. Metilkavikol oranı \% 23.00'den \% 71.67'ye kadar değişim gösterirken, limonen ve fenkon oranları sirasiyla \% 4.03'den \% 41.34'e ve \% 3.51'den \% 17.85'e kadar değişim göstermiştir. En yüksek metilkavikol 
içeren yağlar kurutulmuş yeşil meyve (\% 71.67) ve çiçeklerden (\% 71.06) elde edilmişken, en yüksek limonen (\% 41.34) içeren uçucu yağ ise yapraklardan elde edilmiştir. Saplardan elde edilen uçucu yağlarda ise diğer organlardan elde edilen yağlara kıyasla karvakrol (\% 11.60) içeriğinin yüksekliğiyle dikkatleri çekmiştir.

Rezene meyvesi üzerinde yapılan bazı çalışmalarda (Stefanini ve ark., 2006; Açıkgöz ve Kara, 2020) uçucu yağın ana bileşeni olarak trans-anethol belirlenmişken bu çalışmada rastlanmamıştır. Bunun nedeni çalışmalarda kullanılan bitki materyalinin alt tür ve/veya varyete farklılıkları olabileceği gibi yeşil olum döneminde hasat edilmiş olmasıyla da açıklanabilir (Chung ve ark., 1999; Stefanini ve ark., 2006; Telci ve ark., 2019; Açıkgöz ve Kara, 2020). Çünkü tohumların hasat zamanının gelişim dönemlerine bağlı olarak değişmesi uçucu yağin kimyasal kompozisyonunda değişime neden olduğu yapılan çalışmalarla ortaya konmuştur (Mammadov, 2014).

Çizelge 4. Farklı bitki organlarından elde edilen rezene (Foeniculum vulgare Mill) uçucu yağının bileşenleri (\%) Table 4. Components of fennel (Foeniculum vulgare Mill) essential oil obtained from different plant organs (\%)

\begin{tabular}{|c|c|c|c|c|c|c|}
\hline \multirow[t]{2}{*}{ S.No } & \multirow{2}{*}{$\begin{array}{l}\text { R.T. } \\
\text { (Retention time) }\end{array}$} & \multirow{2}{*}{$\begin{array}{l}\text { Bileşenler } \\
\text { (Components) }\end{array}$} & \multicolumn{4}{|c|}{ Morfogenetik varyabilite (Morphogenetic variability) } \\
\hline & & & $\begin{array}{l}\text { Çiçek } \\
\text { (Flower) }\end{array}$ & $\begin{array}{l}\text { Yaprak } \\
\text { (Leaf) }\end{array}$ & $\begin{array}{l}\text { Sap } \\
\text { Stem) }\end{array}$ & $\begin{array}{l}\text { Yeşil meyve } \\
\text { (Green fruit) }\end{array}$ \\
\hline 1 & 11.10 & $\alpha$-Pinene & 0.50 & 1.64 & 1.98 & 1.18 \\
\hline 2 & 15.02 & Sabinene & - & - & - & 0.26 \\
\hline 3 & 16.82 & $b$-Myrcene & 0.42 & 2.04 & 1.47 & 0.81 \\
\hline 4 & 16.97 & $\alpha$-Phellandrene & 2.75 & 17.43 & 13.87 & 0.89 \\
\hline 5 & 18.46 & Limonene & 6.95 & 41.34 & 13.21 & 4.03 \\
\hline 6 & 18.94 & b-Phellandrene & 0.48 & 1.82 & 1.41 & 0.78 \\
\hline 7 & 19.93 & b-Ocimene & - & 0.41 & 0.29 & - \\
\hline 8 & 21.55 & $p$-Cymene & - & 1.31 & 0.88 & - \\
\hline 9 & 20.45 & $\gamma$ Terpinene & 0.32 & - & - & 0.59 \\
\hline 10 & 26.80 & Fenchone & 15.81 & 3.51 & 6.49 & 17.85 \\
\hline 11 & 30.07 & Fenchyl acetate & 1.08 & 6.61 & 8.05 & 0.46 \\
\hline 12 & 31.08 & Camphor & 0.36 & - & - & 0.37 \\
\hline 13 & 32.57 & Fenchyl alcohol & - & - & - & 0.30 \\
\hline 14 & 33.57 & $B$-Caryophyllene & - & 0.31 & 0.38 & \\
\hline 15 & 35.67 & Methylchavicol & 71.06 & 23.00 & 40.06 & 71.67 \\
\hline 16 & 40.21 & Anethole & - & - & 0.32 & - \\
\hline 17 & 48.53 & Thymol & - & - & - & 0.24 \\
\hline 18 & 49.25 & Carvacrol & 0.28 & 0.58 & 11.60 & 0.59 \\
\hline
\end{tabular}

Tohumun olgunlaşma dönemi ilerledikçe genelde trans-anetol oranında bir artış olmaktadır (Bernath ve ark., 1999; Chung ve ark., 1999; Stefanini ve ark., 2006; Rather ve ark., 2016; Mammadov, 2014). Çalışmada rezene bitkisinin yapraklarından elde edilen uçucu yağda tespit edilen limonen (\% 41.34) oranı, Stefanini ve ark. (2006)'nın farklı dönemlerde yapılan hasatlarda bitki yapraklarında belirlemiş oldukları limonen oranıla (\% 34.48-42.30) benzerlik gösterdiği tespit edilmiştir.

Türkiye'de yürütülen bazı çalışmalar, Türk rezenelerinden elde edilen uçucu yağın ana bileşeninin trans-anethol olduğunu bildirilirken (Coban ve ark., 2018; Telci ve ark., 2019), bazı çalışmalarda ise metilkavikolun ana bileşen (Özcan ve Akgul, 2001; Özcan ve Chalchat, 2006) olduğu ifade edilmiştir. Bu çalışma ise bitkinin farklı organlarına bağlı olarak değişmekle birlikte ana bileşenin yaprak hariç metilkavikol olduğunu ortaya koymuştur.

\section{SONUÇ ve ÖNERİLER}

Yapılan çalışmada elde edilen değerler topluca 1 değerlendirildiğinde rezene bitkisinin farkh organlarına bağlı olarak elde edilen ürünlerin kuru drog oranları, uçucu yağ oranları ve uçucu yağın kimyasal kompozisyonlarının değiştiği tespit edilmiştir. Bitkinin sap, yaprak, çiçek ve kurutulmuş yeşil meyvede uçucu yağ oranlarının iki yılın ortalaması olarak sirasiyla $\% 1.10, \% 2.49, \% 5.51$ ve $\%$ 5.75 olduğu belirlenmiştir. Sap, çiçek ve meyveden elde edilen uçucu yağlarda metilkavikol (sırasıyla \% $40.06, \% 71.06$ ve \% 71.67) ana bileşen olarak tespit edilirken, yapraktan elde edilen uçucu yağda ise ana bileşen olarak limonen (\% 41.34) tespit edilmiştir.

\section{Araştırmacıların Katkı Oranı Beyan Özeti}

Yazarlar makaleye eşit oranda katkı sağlamış olduklarmı beyan eder.

\section{Çıkar Çatışması Beyanı}

Makale yazarları aralarında herhangi bir çıkar çatışması olmadığını beyan ederler. 


\section{KAYNAKLAR}

Açıkgöz MA, Kara ŞM 2020. Morphogenetic, Ontogenetic and Diurnal Variability in Content and Constituents of Bitter Fennel (Foeniculum vulgare Miller var. vulgare) Essential Oil. KSU J. Agric Nat 23 (1): $127-134$.

Açıkgöz MA, Kara SM, Aruc C, Ay E 2017. Morphogenetic, Ontogenetic and Diurnal Variability in Antimicrobial Activity of Bitter Fennel (Foeniculum vulgare Miller var. vulgare) Essential Oil. Indian Journal of Pharmaceutical Education and Research 51(3): 190-194.

Açıkgöz N 1993. Tarımda Araştırma ve Deneme Metotları. Ege Üniversitesi Ziraat Fakültesi. Yayın No: 478. İzmir.

Al-Snafi AE 2018. The Chemical Constituents and Pharmacological Effects of Foeniculum vulgare - A review. OSR Journal of Pharmacy www.iosrphr.org (e)-ISSN: 2250-3013, (p)-ISSN: 2319-4219. 8(5): 8196.

Badgujar SB, Patel VV, Bandivdekar AH 2014. Foeniculum vulgare Mill: A Review of Its Botany, Phytochemistry, Pharmacology, Contemporary Application, and Toxicology. Biomed Research International 10: 1-32.

Bernath J, Nemeth E, Petheo F, Mihalik E, Kalmain K 1999. Regularities of the Essential Oil Accumulation in Developing Fruits of Fennel (Foeniculum vulgare) and its Histological Background. J. Essent. Oil Res. 11:431-438.

Bhardwaj S, Rashmi PV 2019. Effect of Seasonal Variation on Chemical Composition and Physicochemical Properties of Hedychium spicatum Rhizomes Essential Oil, Journal of Essential Oil Bearing Plants 1593-1600.

Choi EM, Hwang JK 2004. Anti-Inflammatory, Analgesic and Antioxidant Activities of The Fruit of Foeniculum vulgare. Fitoterapia.75: 557-565.

Chung HG, Nemeth E, Hethelyi E 1999. Studies on The Essential Oil of Different Fennel (Foeniculum vulgare Mill) Populations During Ontogeny. International Journal of Horticultural Science 5(34): $27-30$.

Coban C, Ozer H, Ors S, Sahin U, Yildiz G, Cakmakci T 2018. Effects of Deficit Irrigation on Essential Oil Composition and Yield of Fennel (Foeniculum vulgare Mill) in A High-Altitude Environment. Journal of Essential Oil Research 30(6): 457-463.

Çalışkan UK, Özçelik B, Sazlı A, Sezik E 2010. Foeniculum vulgare Mill. Aktar ve Kültür Örneklerinin Uçucu Yağlarının Avrupa Farmakopesine Uygunluğu ve Antimikrobiyal Aktivite Yönünden Karşılaştırılması. Ankara Üniversitesi Ecz. Fak. Dergisi 39 (3):195-210.

Giachino RRA, Avcı AB 2020. ISSR-Based Molecular Variation of Some Fennel (Foeniculum Vulgare Mill.) Populations. Anadolu Tarım Bilim. Derg. 35:140-146.
He W, Huang B 2011. A Review of Chemistry and Bioactivities of A Medicinal Spice: Foeniculum vulgare. Journal of Medicinal Plants Research 5(16): 3595-3600.

Kara SM, Acikgoz MA 2018. Morphogenetic, Ontogenetic and Diurnal Variability in Antioxidant Activity, Total Phenol and Flavonoids of Foeniculum vulgare Miller var. vulgare Extracts. YuzuncuYil University Journal of Agricultural Sciences 28 (Special issue): 96-101.

Katar N, Katar D, Temel R, Karakurt S, Bolatkıran I, Ylldız E, Soltanbeigi A 2019. The Effect of Different Harvest Dates on The Yield and Quality Properties of Rosemary Rosmarinus officinalis L. Plant. Biological Diversity and Conservation 12(3):7-13.

Khan M, Musharaf S 2014. Foeniculum vulgare Mill. A Medicinal Herb. Medicinal Plant Research. 4(6): 46-54.

Khorshidi J, Tabatabaei MF, Omidbaigi R, Sefidkon F 2009. The Effect of Different Densities of Planting on Morphological Characters, Yield, and Yield Components of Fennel (Foeniculum vulgare Mill cv. Soroksary). Journal of Agricultural Science 1(2): 6673.

Mammadov R 2014. Tohumlu Bitkilerde Sekonder Metabolitler. Nobel Akademik Yayıncılık, Yayın No:841, ISBN: 978-605-133-743-2. S:412.

Moura LS, Raul N, Carvalho J, Mirian B, Lin C, Angela A 2005. Supercritical Fluid Extraction from Fennel (Foeniculum vulgare), Global Yield, Composition and Kinetic Data. Journal of Supercritical Fluid 35:212-219.

Özcan M, Akgul A 2001. Chemical Composition of The Essential Oil of Bitter Fennel (Foeniculum vulgare subsp. piperitum). Journal of Spices and Aromatic Crops 10(1): 49-50.

Özcan MM, Chalchat JC, 2006. Effect of Collection Time on Chemical Composition of the Essential Oil of Foeniculum vulgare subsp. piperitum Growing Wild in Turkey. European Food Research and Technology 224: 279-281.

Punetha D, Tewari G, Pande C, Bhatt S 2019. Effect of Climatic Conditions on the Volatile Compounds of the Aerial Parts of Foeniculum vulgare Mill., Journal of Essential Oil Bearing Plants 1093-1103.

Rather MA, Dar BA, Sofi SN, Bhat BA, Qurishi MA 2016. Foeniculum vulgare: A Comprehensive Review of Its Traditional Use, Phytochemistry, Pharmacology and Safety. Arabian Journal of Chemistry 9(2): 1574-1583.

Reily K 2013. On Farm and Fresh Produce Management (Part II, p:198-234). in B.K. Tiwari, Brunton, N.P. and Brennan, C.S. (ed.) Handbook of Plant Food Phytochemicals Sources, Stability and Extraction, ISBN 978-1-4443-3810-2 (hardback: alk. Paper), this edition first published 2013 (C) 2013 by John Wiley \& Sons, Ltd., The Atrium, Southern Gate, Chichester, West Sussex, PO19 8SQ, UK. 
Shubham PS 2019. A Comprehensive Review on Pharmacological Activity of Foeniculum vulgare. Global Journal of Pharmacy/Pharmaceutical Sciences 7(1): 1-5.

Stefanini MB, Ming LC, Marques MOM, Facanali R, Meireles MAA, Moura LS, Marchese JA, Sousa LA 2006. Essential Oil Constituents of Different Organs of Fennel (Foeniculum vulgare var. vulgare). Rev. Bras. Pl. Med., Botucatu. 8: 193-198.
Telci I, Dirican A, Elmastas M, Akşit H, Demirtas I 2019. Chemical Diversity of Wild Fennel Populations from Turkey. Journal Applied Research Medicinal and Aromatic Plants 13: 1-5.

Wahba HE, Ibrahim ME, Mohamed MA 2018. Comparative Studies of the Constituents of Fennel Essential Oils Extracted from Leaves and Seeds with Those Extracted from Waste Plants After Harvest. Journal of Materials and Environmental Sciences 9(7): 2174-2179. 